of a great body of direct and indirect evidence, and in the second, the proof, by C. F. M. Swynnerton and W. A. Lamborn, that butterflies, after being eaten by birds, are soon rendered unrecognisable save by the use of the microscope. The further result has followed that McAtee, although he attempts no explanation or defence of his earlier figures, now records the remains of butterflies (24 in the larval, 2 in the pupal state), in 113 out of 80,000 stomachs. To search with the compound microscope for butterfly wing-scales scattered through the contents of 80,000 avian digestive tracts would be a serious business, and if it had been accomplished I venture to believe that far more positive results would have been obtained.

Apart from butterflies and moths and some other specially delicate forms, it is well known, and, so far as I am aware, has never been disputed, that the group and sometimes even the species of insect is readily recognisable when present in a bird's stomach.

It would be inconvenient, within the scope of a letter, to make any further comment on McAtee's two papers and on B. P. U.'s other conclusions founded upon the second. ${ }^{3}$ A detailed reply, now in course of preparation, will, it is hoped, appear in the near future.

\section{Oxford University Museum,} EDward B. Poulton. July 13.

1 Nature, July 9, 1932, p. 66.

2 Proc. Acad. Nat. Sci., Philadelphia, June 1912, p. 281.

3 Smithsonian Miscellaneous Collections, vol. 85, No. 7, p. 201. Washington, 1932 .

B. P. U.'s article on "The Value of 'Protective' Adaptations of Animals" in Nature of July 9 demands some comment. The issue can only be finally settled by ad hoc experimentation; there has already been a certain amount of this, and on the whole it has given evidence of discriminative rejection of certain types.

That, however, can be dealt with by those more familiar with the details of the work than I am. I would here only like to point out what I believe to be a fundamental fallacy in the conclusions summarised by B. P. U.

The arguments put forward appear to be threefold :

(1) The number of insects found in birds' stomachs is proportionate to their numbers in Nature. The proportionality, however, is admitted to be rough only.

(2) Even groups which are usually said to be specially protected are eaten. "Some birds eat ants in very large numbers."

(3) Some organisms which are known to be poisonous are freely eaten, though this causes the death of their captors.

With regard to the first point, it is, I think, relevant to point out that if an inquiry were held we should doubtless discover that the number of ships of different type which are wrecked are roughly in proportion to their numbers, whether they are equipped with Diesel or steam engines, with this or that type of steering gear, this or that type of compass. Again, the number of war vessels of different types sunk by enemy gunfire during the War would doubtless prove to be roughly proportional to their numbers, irrespective of the thickness of their armour-plating. So long as the proportionality is rough, such facts have no relevance whatever to the question of whether the armour-plating, the type of compass, etc., have functional value for navigation. Even if the proportionality were exact, it would have little significance. All ships have to be 'adapted' to navigation in a number of ways if they are to survive the dangers of the sea at all : those that are 'worse adapted' in regard, for example, to compass or power, deliberately do not take such risks as others, but stick to coastwise traffic, and do not put out when 'better adapted' boats would not hesitate: their 'adaptation' is in their habits.

So with organisms. They all have to be adapted in a thousand ways if the species is to persist. With regard to avoiding their enemies, some do so by stressing protective coloration, others by protective and retiring habits, others by high fecundity, others by distastefulness, others by toughness, others by speed, etc. The avoidance of enemies is never perfect; but this does not in the least invalidate the fact that to achieve survival numerous adaptations have been necessary. We should also remember that a certain number of protectively coloured animals will of necessity be discovered, a certain number of warningly coloured ones eaten. The absolute number, and also the proportion, will increase with $(a)$ the abundance of the species itself, $(b)$ the hunger of the enemy species. This mechanism helps to produce the rough proportionality between abundance and number eaten; but it tells us nothing as to whether the total abundance would not have been quite different if the colour were not adaptive.

One has only to imagine an organism which was conspicuous in colour and in habits, sluggish, palatable, juicy and soft, and with a low fecundity. How long would the species survive? I take it, about as long as a type of ocean-going ship with no compass or steering gear.

A species is only adapted to survive, not to become immune from all enemies (which would, in any case, lead to destruction through over-multiplication); and each adaptation is relevant only in its particular way.

As regards point (2), it is a well-known fact that adaptation for protection is frequently met by counter-adaptation for attack. The fact that "some birds " (B. P. U.'s own words) eat ants freely does not imply that ants are not rejected, relatively or entirely, by most birds. To deny this is like denying that submarines are particularly immune from detection by most ships, on the ground that by special methods they can often be located and destroyed by depth charges.

Point (3) may or may not mean anything. Without precise investigation directed especially to the ecology of the species, it is impossible to say whether or not the poison or the distastefulness may not actually confer protection against other organisms than those which do eat them. This is really a variant of the answer to point (2). Some plants are in general poisonous, and appear to be therefore immune from being used as food by most insects; but they are eaten by insects which possess a special immunity (cf. certain Papilios).

In general, the fallacy is that of forgetting that no species of organism could exist which was not a bundle of adaptations, but that each particular adaptation is partial and relative.

King's College, London.

$$
\text { Julian S. Huxley. }
$$

\section{Degenerative Mutations}

IN Mrs. Sexton's important paper ${ }^{1}$ on " Degeneration and Loss of the Eye in the Amphipod Gammarus chevreuxi" she makes one remark which, in its sug. gestion of theoretical controversy, is in striking contrast with the mass of details of observation, and minute records of genetical facts, of which the rest of the paper consists. The sentence to which I refer is : "In view of all that has been written on the origin of the blind fauna, it is a significant fact that blind animals could be produced within the limits of a single species in such a short time and in so few generations".

This means, apparently, that the blindness of cave 